Saudi Journal of Oral and Dental Research

Abbreviated Key Title: Saudi J Oral Dent Res

ISSN 2518-1300 (Print) |ISSN 2518-1297 (Online)

Scholars Middle East Publishers, Dubai, United Arab Emirates

Journal homepage: https://saudijournals.com/sjodr

Review Article

\title{
Round Cell Tumors - A Brief Overview!
}

Addanki Naga Valli Anusha (B.D.S) ${ }^{1 *}$, Dr. Divya Uppala M.D.S ${ }^{2}$, Dr. B. Alekhya B.D.S (M.D.S) ${ }^{3}$, Dr. Kalyan Kanth K, $\mathrm{MDS}^{4}$

${ }^{1}$ House Surgeon GITAM Dental College \& Hospital, Visakhapatnam -45, India

${ }^{2}$ Associate professor, Dept of Oral Pathology \& Microbiology, GITAM Dental College \& Hospital, Visakhapatnam -45, India

${ }^{3}$ Postgraduate Student, Dept of Oral Pathology \& Microbiology, GITAM Dental College \& Hospital, Visakhapatnam -45, India

${ }^{4}$ Oral and Maxillofacial Surgeon, Marripalem, Visakhapatnam -45, India

DOI: $\underline{10.36348 / \text { sjodr.2020.v05i08.002 }}$

| Received: 28.06.2020 | Accepted: 06.07.2020 | Published: 06.08.2020

*Corresponding author: Addanki Naga Valli Anusha

\section{Abstract}

A group of neoplasms that share the characteristic light microscopic appearance of being composed of relatively small, round to round-spindled, monotonous, seemingly undifferentiated cells. It comprises all significant categories of neoplasms- carcinomas, sarcomas, lymphomas, and neuroendocrine- neuroectodermal tumors. Hence microscopic similarity between them and the diagnosis in routine histologic examination extremely difficult. This heterogeneous group of lesions becomes a diagnostic challenge. The diagnosis depends on clinical, radiological, pathological and genetic features. Each lesion has its own has distinctive features but histopathologically termed as 'round cell tumors'. This article provides an insight into this group of intriguing round cell lesions, which are characterized by varied histopathological features and their associated confirmatory immuno-histochemical markers for a reliable and a consistent diagnosis.

Keywords: round cell lesions, round -spindle cells, histopathology of undifferentiated cells.

Copyright @ 2020: This is an open-access article distributed under the terms of the Creative Commons Attribution license which permits unrestricted use, distribution, and reproduction in any medium for non-commercial use (NonCommercial, or CC-BY-NC) provided the original author and source are credited.

\section{INTRODUCTION}

Round cells are unified by morphology, differing widely by histogenesis. It generally contains sheets round cell which are small having large nucleus, scant cytoplasm, hyperchromatic or vesicular nucleus. They are mostly highly undifferentiated neoplasms composed of a monotonous population of round cells with high Nuclear: Cytoplasm ratio.

Histological similarity, undifferentiated and primitive character makes it difficult to diagnose the condition especially if the tumors are poorly differentiated. Therefore, the possibility of a definitive diagnosis seems to be plausible. Hence, light microscopic histology remains a gold standard in diagnosis followed by immunohistochemical evaluation [1].

Probable classification attempts were made in the year 2017, Sharma et al classified round cell tumors as following:

\section{On the basis of round cell pattern}

Diffuse round cell pattern: Ewing's sarcoma, Primitive neuroectodermal tumor (PNET) Merkel cell carcinoma embryonal rhabdomyosarcoma (ERMS)
Small cell carcinoma Lymphoma Leukemic infiltrate. Further, in Ewings Sarcoma and $t$ Alveolar rhabdomyosarcoma (ARMS) can be divided by fibrous septate.

Alveolar/pseudoalveolar round cell pattern: This pattern often consists of focal or poorly cohesive cell population mainly of round cells organized in pseudoalveolar pattern. Alveolar rhabdomyosarcoma (ARMS), Peripheral Neurectodermal Tumor.

Round cell pattern with rosettes: A rosette' is used when the round cells are radially arranged around a central area like a flower. These are called as Flexner Winterstin rosettes. The next type is the Homer Wright rosette: This type of rosette has no lumen centre, but abundant fibrillary material most commonly seen in neuroblastoma.

Hemangiopericytomatous vascular pattern is seen in poorly differentiated synovial sarcoma, Mesenchymal chondrosarcoma. Here, the round cell patterns are arranged with other components such as Pseudo glands. Frequently, this pattern can be visualized in cartilage form of mesenchymal chondrosarcoma. 


\section{According to the size of round cell}

Round cells were also based on size, frequently seen in Squamous cell carcinoma, PNET, Ewing's sarcoma, melanoma, rhabdomyosarcoma (RMS), Langerhans cell disease, lymphoma, adenocarcinoma, neuroendocrine carcinoma, Merkel cell carcinoma and olfactory neuroblastoma.

The large round cell type can be found in Squamous cell carcinoma, adenocarcinoma, melanoma, RMS, lymphoid tumors, paraganglioma.

\section{On the basis of origin: They were classified based on origin:}

Neurogenic origin: Ewing's sarcoma/PNET, neuroblastoma, retinoblastoma, medulloblastoma, Merkel cell tumor, paragangliomas, small cell tumor of lung Mesenchymal origin.

Myogenic differentiation: ERMS, ARMS.

Osteoid differentiation: Small cell osteosarcoma.

Chondroid differentiation Mesenchymal chondrosarcoma.

Adipose tissue like differentiation can be seen in Myxoid/round cell liposarcoma. Hematolymphoid origin Lymphoma.

Malignant soft tissue tumors of uncertain type: Desmoplastic small round cell tumor (DSRCT) and Poorly differentiated synovial sarcoma.

\section{Based on Histopathological patterns}

EWING'S SARCOMA: They are composed of solid sheets or masses of small round cells with little stroma, few connective tissue septa may be present. The cells are small, round, large round or ovoid nuclei, dispersed chromatin, scanty cytoplasm, hyperchromasia, indistinct borders. The cells are arranged in Filigree pattern and are glycogen positive. Mitotic figures, geographic necrosis with perivascular sparing is observed along with Rosettes, tiny vascular channels, hemorrhage with vascular lakes [2].

Immunohistochemical studies exhibits: The cells show membranous expression of CD99 or MIC 2. Depending on degree of neuroectodermal differentiation, cells express neuron-specific enolase, synaptophysin and S-100 protein. FLI1 positivity in nucleus and is specific for EFTs [3].

\section{Rhabdomyosarcoma}

It is a malignant tumor, relatively uncommon and of striated muscle origin. Round eosinophilic cells are large and intermediate size with a small nucleus, granular eosinophilic cytoplasm, interspersed among other cell types. The other types include broad elongated eosinophilic cells with cross striations and Small round as well as spindle cells with dark-staining nuclei and little cytoplasm. Well-differentiated tumors consist of elongated, strap/ tadpole shaped rhabdomyoblasts with fibrous and myxoid stroma.
Racquet cell are the characteristic feature of pleomorphic type with large bizarre cells, nuclei at the expanded end of the cell.

In the Botryoid pattern of EMS, the characteristic feature is diffuse, myxoid or mucoid matrix with sparsely scattered primitive mesenchymal cells and a cambium layer with peripheral zone of increased cellularity[4]. Alveolar rhabdomyosarcoma: The feature of occurrence of small, poorly differentiated round, oval cells aggregated into clusters separated by fibrous septa is characteristic.

\section{Neuroblastoma}

Histologic Features: Consists of densely packed masses of small darkly staining cells with a poorly defined cytoplasm and a regular round vesicular/stippled nucleus (Image 2). Rosette formation observed with pseudoglandular structure lined by a single layer of non-ciliated columnar cells with a basal nucleus and a cuticular border at the apex of the cells. These resemble the sustentacular and olfactory cells of the olfactory mucosa [5].

It also consists of eosinophilic neurofibrils, pseudorosette formation also observed with mitotic figures in fibrillar neuroid pattern. Immunohistochemical studies have shown CD99 negative but positive for neural markers, Muscle markers, CK, EMA.

Cytogenetic studies have shown EWS/FLI1 transcript negative.

\section{Merkel Cell Carcinoma}

Known as Primary (cutaneous) neuroendocrine carcinoma of skin. Histologically three types of cells observed as following: Trabecular, the least common and often with a ribbon of monotonous round cells. Secondly, the Intermediate: this one quite common often with a nodular growth Round to oval cells, blastlike chromatin and finally, the Small cell type which consists of round to oval cells with salt pepper nuclear chromatin.

The immunohistochemical studies reveal a dot like paranuclear reactivity with CK20 and cytoplasmic membrane expression of chromogranin \& synaptophysin [6].

\section{Lymphomas}

Malignant lymphomas are group of neoplasms having varying degrees of malignancy which are frequently derived from the cells of lymphoid tissue. Non-Hodgkin's Lymphoma histopathologically, has observed Follicular and Nodular as the two types. The characteristic feature was nodular growth pattern in lymph nodes with large clusters of neoplastic cells. 
Two principal cell types observed are Centrocytes; they are small cells, cleaved nuclear contours and scant cytoplasm. Centroblasts are larger cells open nuclear chromatin, several nucleoli and modest amounts of cytoplasm. Burkitt's lymphoma, also known as African Jaw Lymphoma, a high-grade Bcell neoplasm and is one of the fastest growing malignancies. Histopathological features include monoclonal proliferation of $\mathrm{B}$ lymphocytes are observed which are small, uniform non-cleaved cells, in diffuse pattern (Image 1).

The characteristic feature is presence of Burkitt cells which are nearly uniform in size and shape, round to oval nuclei, coarse chromatin, multiple nucleoli, and basophilic vacuolated cytoplasm. This pattern is a result from rapid cell turnover with individual cell necrosis and extensive scavenging of debris by macrophages [7].

Hodgkin's lymphoma: Histopathologically six types were observed, Nodular sclerosis: accounting for nearly $60-80 \%$ of all types where fibrosed bands separate the node into 'nodules'. A special mention to the Lacunar-type RS cell, which has monolobated or multilobated nucleus with small nucleolus and abundant pale cytoplasm observed. Mixed-cellularity accounts for 15-30\% of all types with diffuse classic RS cells type consisting of large, bilobate with large eosinophilic inclusion like nucleolus. Lymphocyte-depleted: This is a rare type with a diffuse and a hypocellular lymphocyte infiltrate.

Characteristics of typical Reed-Sternberg cell are 20-50 micrometers diameter, amphophilic; granular cytoplasm with two mirror-image nuclei (owl eyes) with an eosinophilic nucleolus, thick nuclear membrane admixed with lymphocytes, histiocytes, eosinophils and plasma cells [8].

\section{Plasma Cell Neoplasias}

It consists of proliferation of mature and immature plasma cell and eccentrically placed nuclei with cartwheel appearance. Histopathological features could include a uniform population of poorly differentiated blast cells to mature cells observed within sheets of polyhedral cells. Auer bodies observed contains crystalline rod-like azurophilic intracytoplasmic structures, representing primary lysosomes of myeloid cell precursor.

Immunohistochemical presents with myeloperoxidase, chloracetate esterase, CD 68, CD43 $\& 45$ positivity [9].

\section{CONCLUSION}

The round cell tumors depict a group of highly aggressive and undifferentiated malignant group of tumors consisting of a monotonous population of round cells. The prevalent distribution and heterogeneous histology of different round-cell tumors creates difficulty in diagnosis. Hence, round cell tumors certainly represent the best model of how the integration of different diagnostic tools (morphology, immuno-histochemistry, and molecular genetics) may impact on the accurate diagnosis of tumors.

Previous publications/ presentations: NIL

Source of funding: NIL

Conflicts of interest: NIL

\section{REFERENCES}

1. Rossi, S, G., Nascimento, A.G., Canala, F., Dei Tosa, A.P. (2007). Small round-cell neoplasms of soft tissues: An integrated diagnostic approach. Current Diagnostic Pathology; 13, 150-163

2. Regezi, J.A., Sciubba, J.J., Jordan, R.C.K.(2017). Connective Tissue Lesions. Oral Pathology Clinical Pathologic Correlation. $7^{\text {th }}$ edition. Missouri: Elsevier; 161 - 86

3. Gnepp, D.R.(2009). Soft Tissue Tumors of Head and Neck. Diagnostic surgical pathology of head and neck. $2^{\text {nd }}$ Edition. Philadelphia: Elsevier; 647 . 727.

4. Weiss, S.W.(2008). Goldblum JR. Soft tissue tumours. $5^{\text {th }}$ edition. Philadelphia: Elsevier.

5. Elder, D.E.(2008). Lever's histopathology of skin. $10^{\text {th }}$ edition. Baltimore: Lippincott; 2008.

6. Lengyel, E., Gilde, K., Remenár, E., Esik, O. (2003). Malignant mucosal melanoma of the head and neck - a review. Pathology Oncology Research, 9(1):7-12

7. Essadi, I., Ismaili, N., Tazi, E., Elmajjaoui, S., Saidi, A., Ichou, M., \& Errihani, H. (2008). Primary lymphoma of the head and neck: two case reports and review of the literature. Cases Journal, $1: 426$

8. Thakur, J.S., Minhas, R.S., Mohindroo1, N.K., Sharma, D.R., Mohindroo, S., \& Thakur, A. (2009). Primary non-Hodgkin's lymphoma of the infratemporal fossa: a rare case report. Head \& Neck Oncology, 1:20

9. Kumar, V., Cotran, R.S., Robbin, S.L. (2005). Robbins Basic Pathology. $7^{\text {th }}$ edition. Philadelphia Elsevier. 